\title{
CARDIOVASCULAR AND RESPIRATORY RESPONSES TO SEVERE HYPOXAEMIA DURING ANAESTHESIA
}

\section{The Effect of Various Concentrations of Three Anaesthetic Agents Upon the Cardiovascular Response and Oxygen Transpont}

\author{
H.I.A. NISBET, M.B., CK.B., F.F.A.R.C.S., C.R.C.P. (c); \\ I.G. GRAY, M.B., CH.B., F.F.A.R.C.S.; \\ P.M.OLLEY, M.Br, B.S, M.R.C.P. (LOND.), F.A.C.P.(C); \\ AND A.E. JOHNSTON, M.D., F.R.C.P.(C), \\ WTTH THE TECHNICAL ASSISTANCE OF $G$. VOLgYeSI
}

\begin{abstract}
INTRODUCTION
INEVITABLY, the anaesthetist will continue to encounter hypoxaemia in the course of his practice. The cardiovascular response to hypoxaemia in anaesthetised subjects may depend upon the anaesthetic agent and the depth of anaesthesia. To study this response we subjected dogs to severe arterial hypoxaemia at various depths of anaesthesia with halothane, trichlorethylene and methoxyflurane and measured the changes in oxygen transport, cardiac output, stroke volume and systemic blood pressure during controlled ventilation at constant arterial carbon dioxide tension. Also, in some dogs, we studied changes in myocardial contractility and the effect of beta adrenergic blockade.
\end{abstract}

\section{MethoD}

Beagle dogs 10 to $12 \mathrm{~kg}$ in weight were used in the experiments. Anaesthesia was induced with barbiturate ( $30 \mathrm{mg} / \mathrm{kg}$ ). Each dog was intubated with a cuffed endotracheal tube. Anaesthesia was maintained with:

(1) halothane at end-tidal concentrations (ETH $\%$ ) of 1 per cent ${ }^{*}$ ( 4 dogs), 1.43 per cent ( 3 dogs) and 2 per cent 1 ( 2 dogs);

(2) trichlorethylene at inspired concentrations (IC g) of 0.9 per cent ( $3 \mathrm{dogs}$ ) and 1.5 per cent $(4$ dogs);

(3) methoxyflurane at end-tidal concentrations (ETM 8 ) of 0.30 per cent ${ }^{\circ}$ ( 7 dogs), 0.45 per cent $\uparrow$ ( 7 dogs) and 0.60 per cent $\$$ ( 7 dogs).

From the Departments of Antesthesia and Cardiology, The Research Institute, The Hospital for Sick Children and the Departments of Anaesthesia and Paediatrics, University of Toronto, Toronto, Ontario.

Supported in part by a grant from the Canadian Red Cross Youth (Ontario).

Paper read by Dr. H.I.A. Nisbet at the Canadian Anaesthetists' Society Meeting in Quebec, June 1971 .

"Light anaesthesia.

† Moderately deep anaesthesia.

$\$$ Deep anaesthesia.

Canad. Anaesth. Soc. J., vol. 19, no. 4, July 1972 
These concentrations were monitored by repeatedly analysing end-tidal samples with the Mayo volatile anaesthetic analyser\$ (for halothane and methoxyflurane) and by using a calibrated vaporiser| for trichlorethylene. The dogs were ventilated in such a manner as to maintain end-tidal carbon dioxide concentration $\left(\mathrm{ETCO}_{2}\right)$ constant and close to normal limits: $\mathrm{ETCO}_{2}$ was monitored by analysing end-tidal samples from the trachea with a Beckmann LBI analyser.|| Under fluoroscopy catheters were placed in the aorta and either the right atrium or the pulmonary artery. After anaesthesia had been maintained with the appropriate agent and at the appropriate concentration for at least one hour, we measured the cardiac output ( $Q$ ) by dye dilution, the mean aortic blood pressure (MABP), the heart rate (HR) and the body temperature (by rectal thermometer). Arterial oxygen tension $\left(\mathrm{PaO}_{2}\right)$, carbon dioxide tension $\left(\mathrm{PaCO}_{2}\right)$ and $\mathrm{pH}$ were measured and the results corrected for changes in body temperature. In some dogs anaesthetised with methoxyflurane at 0.46 per cent ET, myocardial contractility was calculated by means of an integrated circuit differentiator and Clark pressure transducer ${ }^{* 0}$. These measurements, made after one hour of ventilation with air and the appropriate anaesthetic agent, are called the controls (C) throughout this paper.

The oxygen content of the inspired gas was then reduced and the dogs were subjected to 20 minutes of hypoxaemia. Between the 10th and 20th minutes we repeated all the measurements, reporting them as hypoxaenia values $(\mathrm{H})$. The collected data revealed the changes in cardiac output, heart rate and mean arterial pressure in response to hypoxaemia and enabled us to calculate stroke volume (SV), total systemic vascular resistance (TSVR) and oxygen transport ( $\mathrm{TaO}_{2}$ ). The significance of the changes due to hypoxaemia was assessed by means of the paired t test.

We then administered propranolol by intravenous injection $(0.2 \mathrm{mg} / \mathrm{kg})$ to the hypoxaemic dogs anaesthetised with methoxyflurane at moderate depth and repeated all the measurements.

\section{RESULTS}

The results of the measurements for controls and during hypoxaemia are shown in Tables I to VII.

Figure 1 illustrates the effect of hypoxaemia on oxygen transport, cardiac output and stroke volume in dogs anaesthetised with the three different agents at various depths of anaesthesia.

During hypoxaemia oxygen transport fell below control values in all the dogs except those moderately deeply anaesthetised with methoxyflurane; in them it rose slightly. The lowest values were seen with deep methoxyflurane anaesthesia and with both depths of trichlorethylene anaesthesia.

Under light anaesthesia cardiac output rose significantly during hypoxaemia whatever the anaesthetic agent. Under deep anaesthesia with methoxyflurane the rise in cardiac output during hypoxaemia was not significant. Under deep anaes-

\$adel 1850, Ohio Medical Products, Madison, Wisconsin 53701.

IGT ritec Type B, Cyprane Ltd, Keighley, England, U.K.

|GBeckman Instruments Ltd, Electronics Instruments Div., Schiller Park, Il]. 60176.

- 0 Clark Physiological Pressure Transducer Type 4-327-0109 CEC/Transducer Division, Monovia, California 91016. 

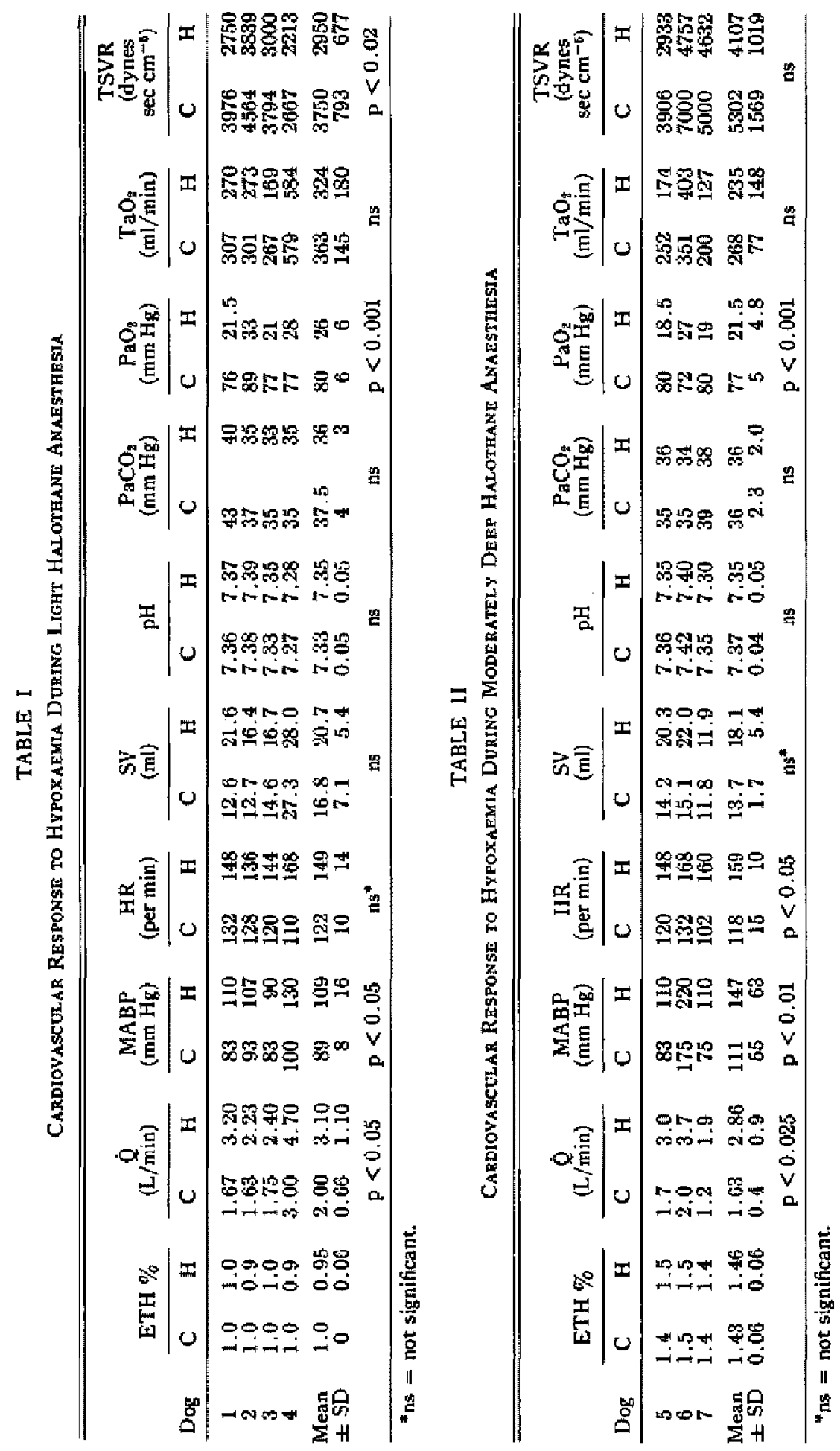

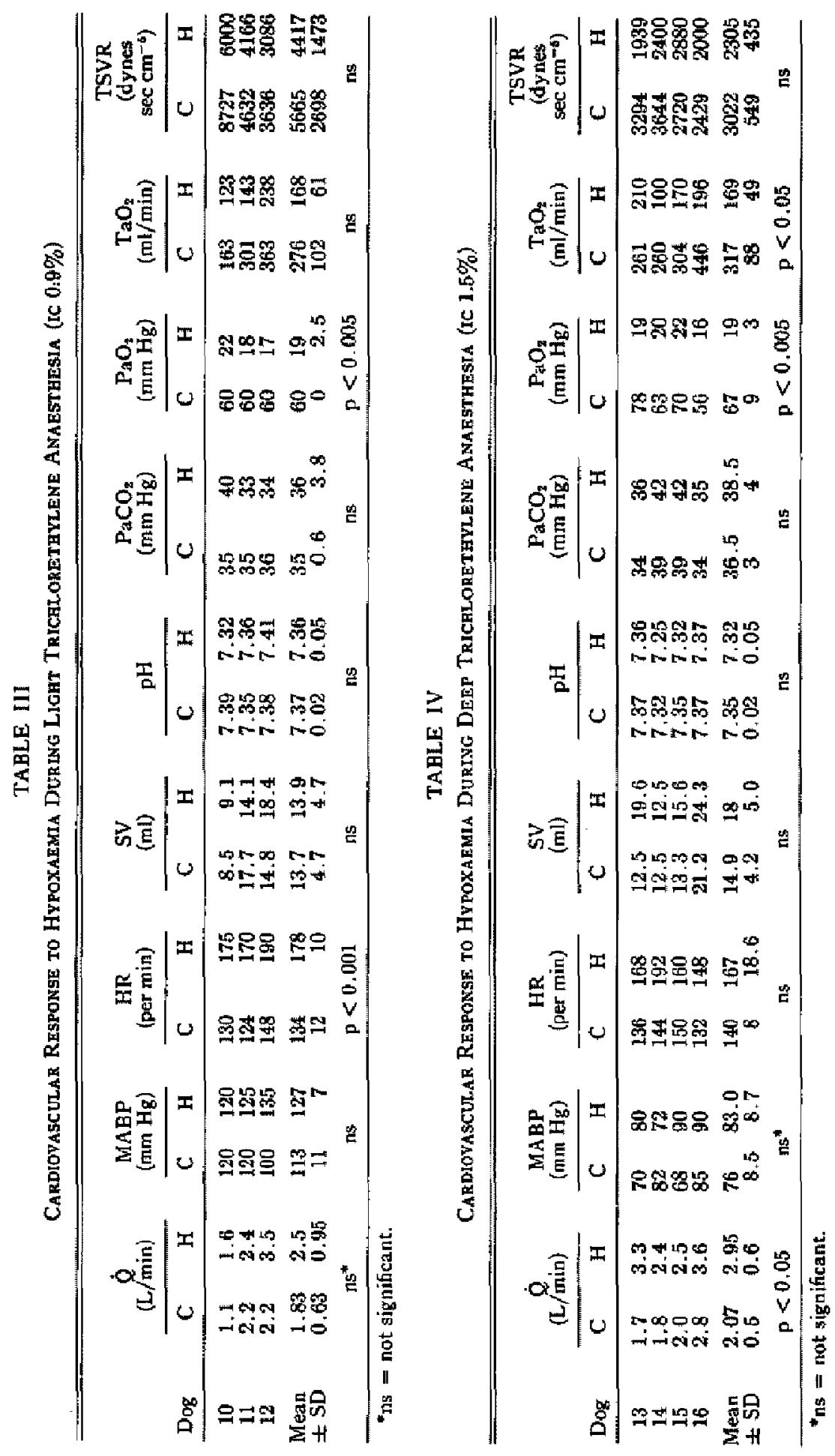

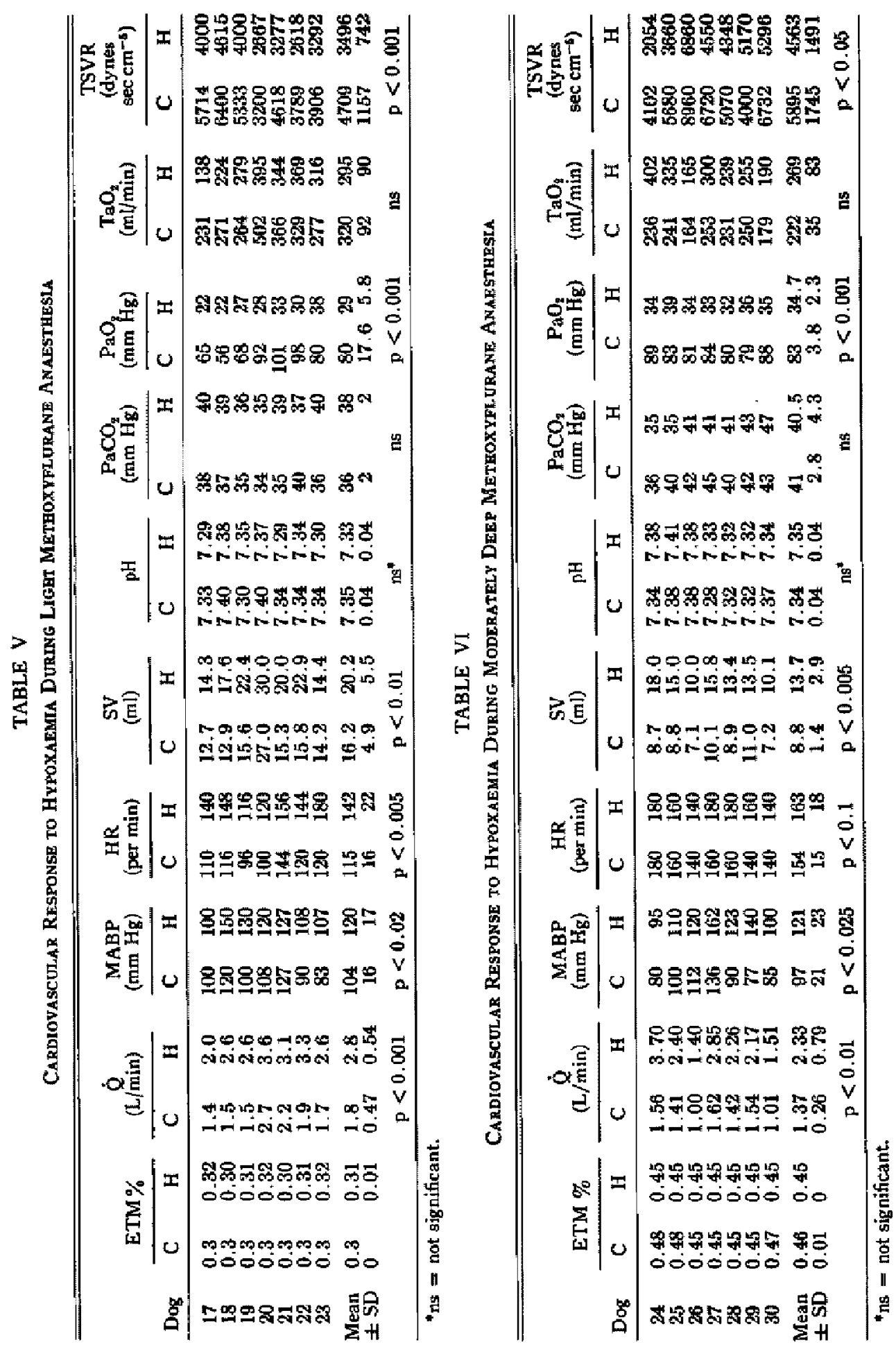


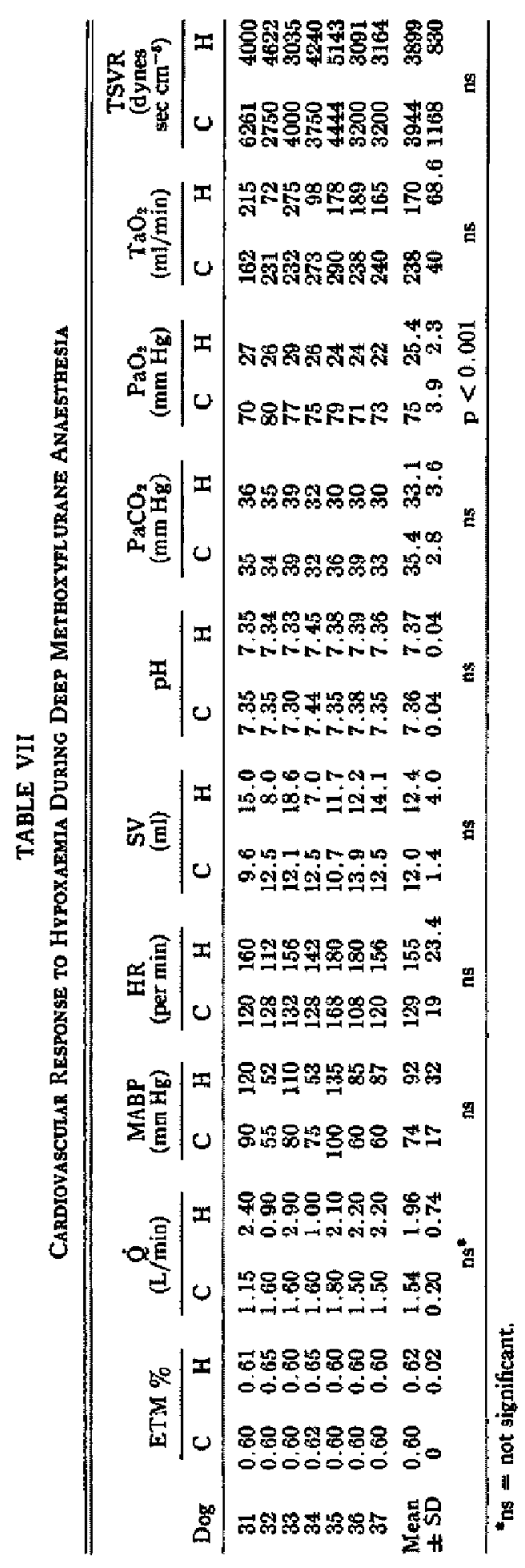




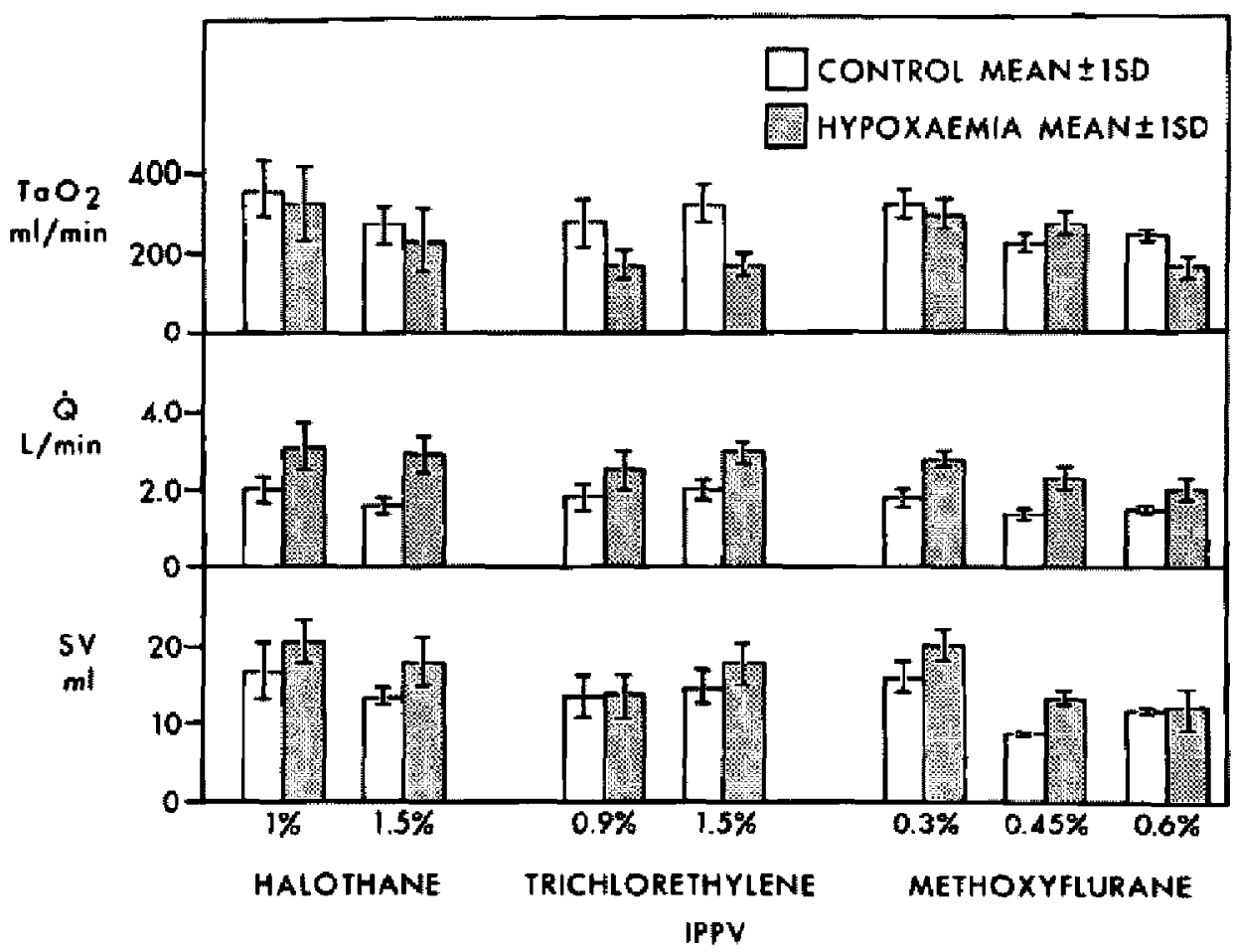

Frguax 1. The effect of hypoxaemia upon oxygen transport, cardiac output and stroke volume under balothane, trichlorethylene and methoxyflurane.

thesia with halothane the dogs (Nos. 8 and 9) died rapidly during hypoxaemia and are therefore not represented in Figure 1, or in the Tables.

Under light anaesthesia stroke volume rose in the dogs anaesthetised with halothane and methoxyflurane. Hypoxaemia during deep anaesthesia with methoxyflurane and light anaesthesia with trichlorethylene caused an insignificant change in stroke volume.

Changes in total systemic vascular resistance, mean aortic blood pressure and heart rate are illustrated in Figure 2.

Total systemic vascular resistance decreased most during hypoxaemia under light anaesthesia. Significant reductions were measured at light and moderate depths of methoxyflurane anaesthesia but not with deep methoxyfurane and trichlorethylene anaesthesia, where the control values were already low.

In all the dogs the heart rate rose during hypoxaemia, the most significant rise being in those under light trichlorethylene anaesthesia.

Hypoxaemia caused the left ventricular $\mathrm{dP} / \mathrm{dt}$ to increase by 93 per cent under moderately decp methoxyflurane anaesthesia. Under deep anaesthesia with the same agent the mean increase was only 38 per cent. At this depth, however, the response was variable and in some dogs decreases in $\mathrm{dP} / \mathrm{dt}$ were recorded. 


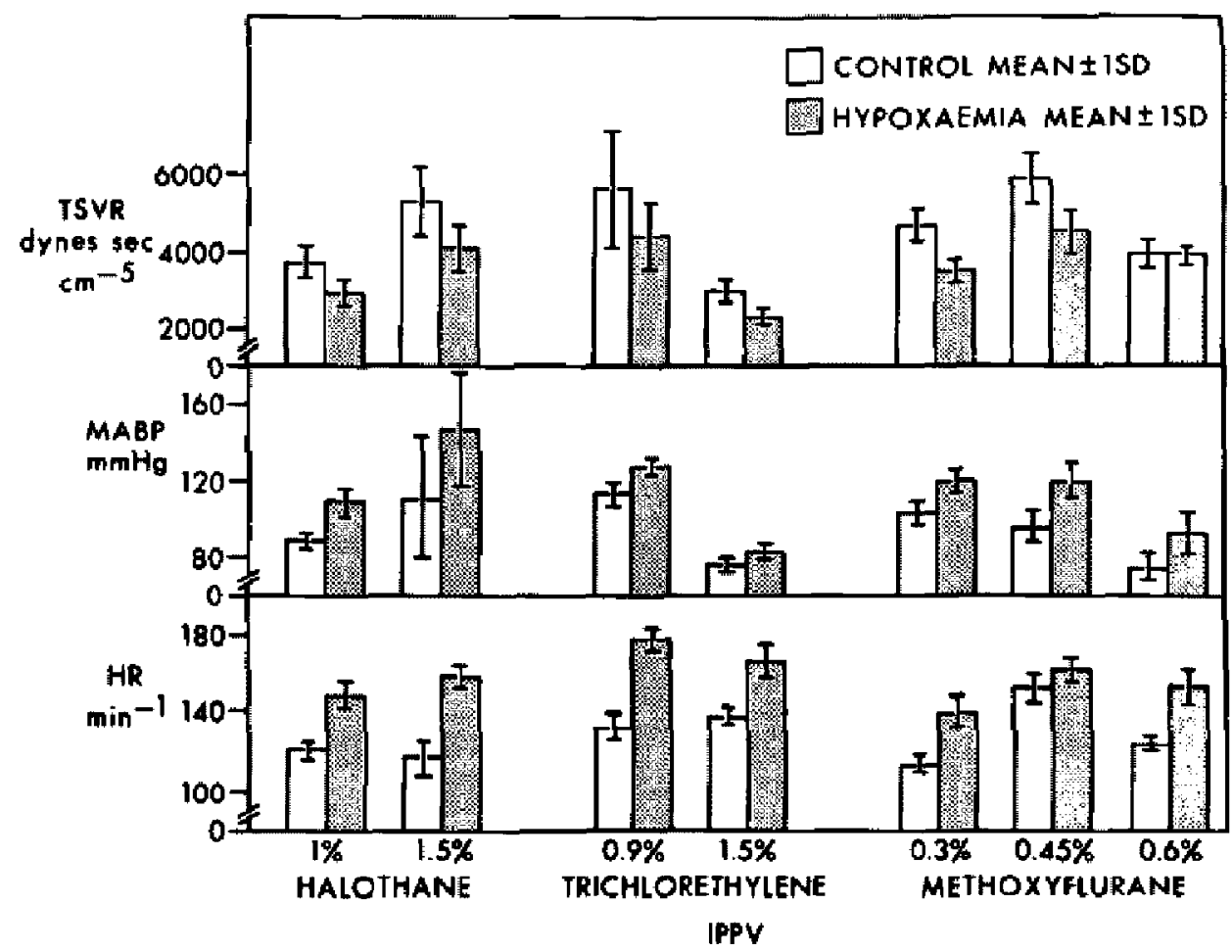

Fycune 2. The ect of hypoxaemia upon total systemic vascular resistance, mean arterial blood pressure and heart rate under halothanc, trichlorethylene and methoxyflurane.

Propranolol caused cardiac output, mean aortic blood pressure and oxygen transport to fall during hypoxaemia and total systemic vascular resistance to increase.

Figure 3 illustrates the degree of arterial hypoxaemia for each agent and level of anaesthesia and shows that under controlled ventilation variations in artenal $\mathrm{CO}_{2}$ tension were prevented and changes in $\mathrm{pH}$ were insignificant.

\section{Discusssion}

End-tidal concentrations of 0.30 per cent, 0.46 per cent and 0.60 per cent methoxyflurane and 1.00 per cent, 1.43 per cent and 2.00 per cent halothane are approximately equivalent to minimum alveolar concentration (MAC) values of $1.3,1.9$ and 2.5 respectively. Normocarbic hypoxia may reduce MAC values to 76 per cent of control values ${ }^{2}$ and this would indicate that our measurements in the hypoxaemic dogs were made at levels of anaesthesia slightly deeper than those indicated by the above MAC values. However, the effects of hypoxaemia with methoxyflurane and halothane anaesthesia appear to have been measured at comparable depttis. No MAC values are avallable for different concentrations of trichlorethylene.

Cullen and Eger found that severe hypoxaemia $\left(\mathrm{PaO}_{2}=30 \mathrm{~mm} \mathrm{Hg}\right.$ ) during anaesthesia with halothane $(0.75-1.25$ per cent end-tidal) stimulated ventilation 


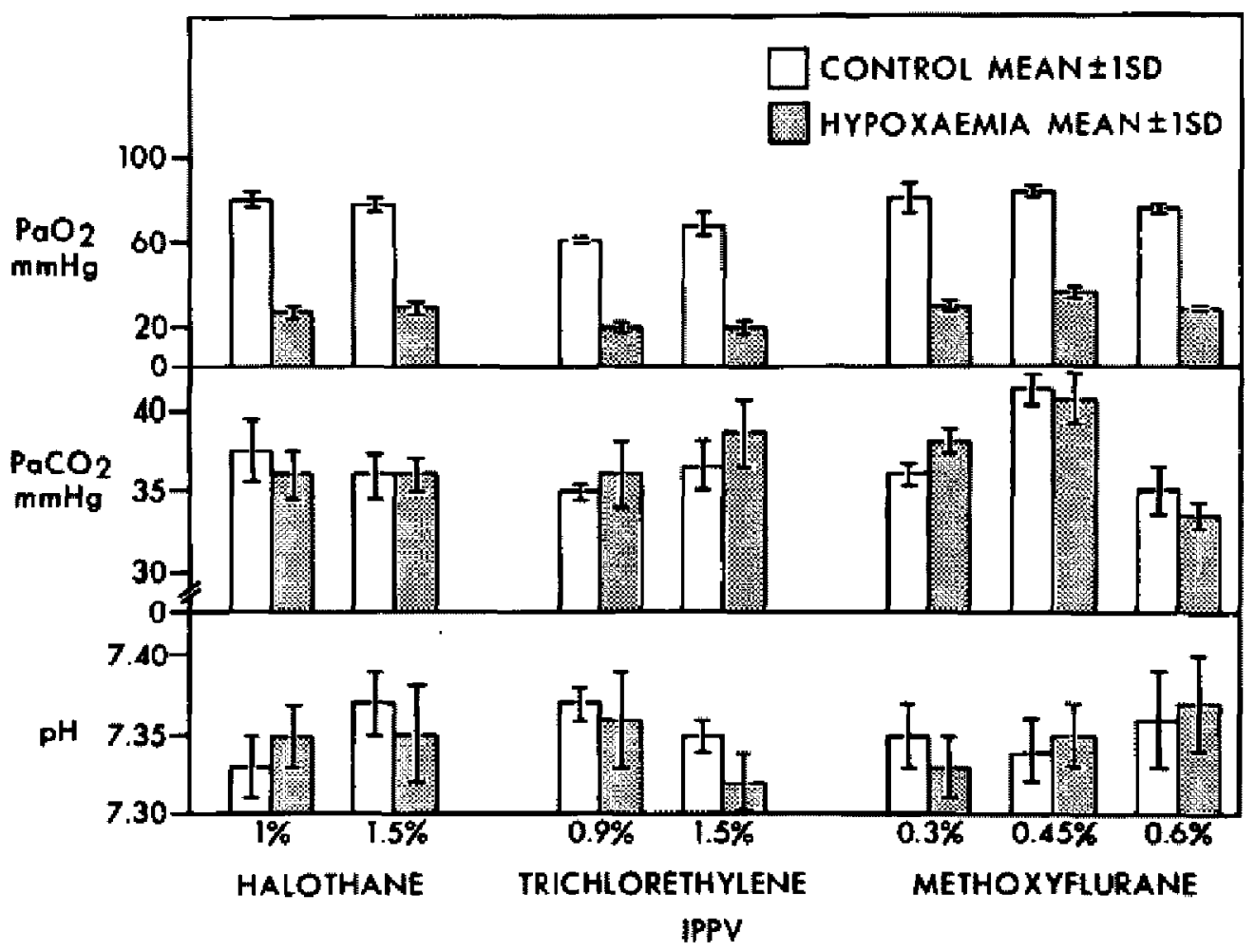

Frgure 3. The effect of hypoxaemia upon arterial oxygen and carbon dioxide tension and pH under halothane, trichlorethylene and methoxyflurane.

and increased cardiac output, but with end-tidal concentrations of 1 to 1.5 per cent respiratory or cardiac arrest occurred, oxygen transport became inadequate and metabolic acidosis developed. Our results agree with their conclusion that hypoxaemia under light halothane anaesthesia stimulates a significant increase in cardiac output so that an insignificant fall in oxygen transport occurs. In our dogs, however, this response was maintained under moderate depths of anaesthesia and only became inadequate at 2.5 MAC. Our results during light anaesthesia are also in general agreement with those of Gorlin and Lewis ${ }^{4}$ who showed that under pentobarbitone anaesthesia dogs could survive severe hypoxaemia for prolonged periods.

The dogs anaesthetised with trichlorethylene should perhaps be considered separately as MAC values are not known and hypoxaemia was of slightly greater severity than in the other groups. A significant fall in oxygen transport occurred in these dogs despite a striking rise in cardiac output. This may be because the oxygen dissociation curve of the dog becomes less steep at an oxygen tension of $20 \mathrm{~mm} \mathrm{Hg}$. In Figure 4 oxygen transport and cardiac output are plotted in relation to $\mathrm{PaO}_{2}$ in dogs under light anaesthesia. Above $25 \mathrm{~mm} \mathrm{Hg}$ oxygen transport remains relatively constant with declining $\mathrm{PaO}_{2}$. Below $25 \mathrm{~mm} \mathrm{Hg}$ a rise in cardiac output is not associated with maintained oxygen transport.

The investigations of Cullen and $\mathrm{Eger}^{3}$ irvolved repeated exposure of each dog to hypoxaemic episodes at varying levels of halothane anaesthesia. Respiratory and 


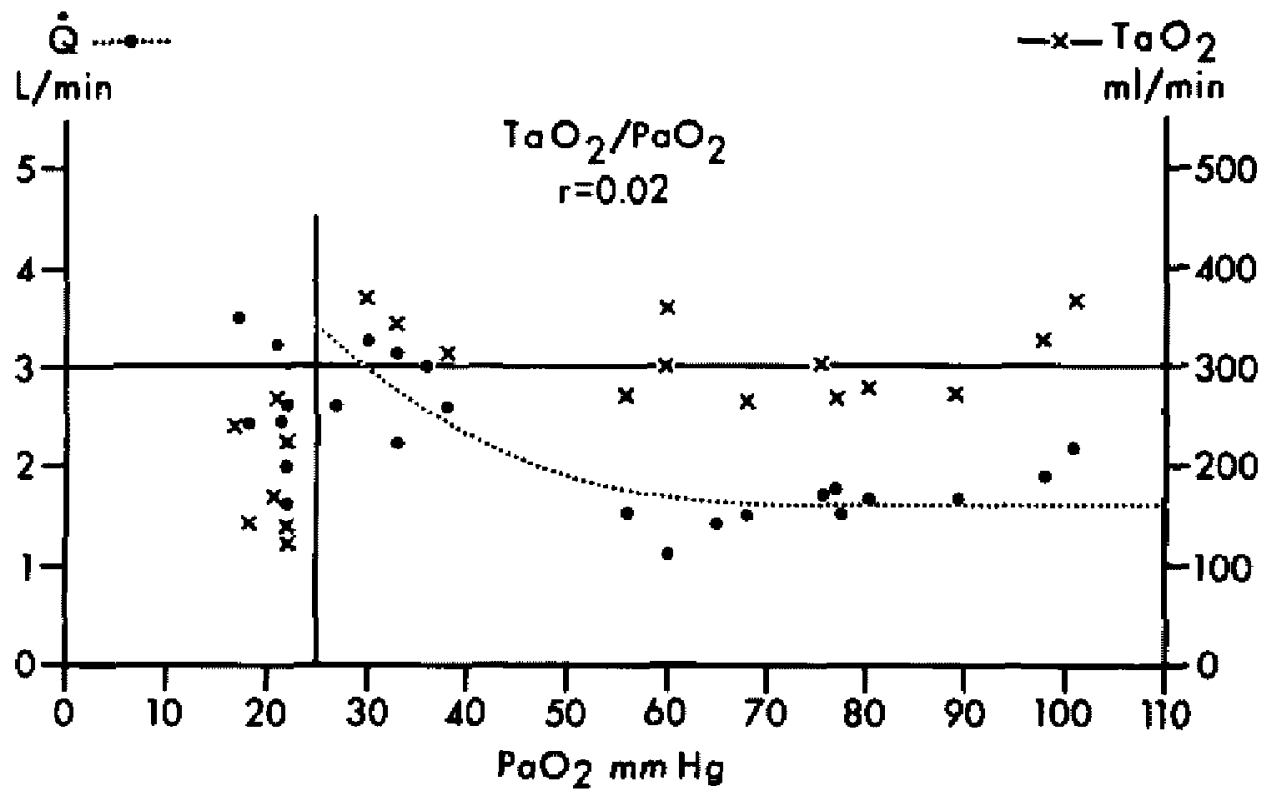

Ficure 4. Oxygen transport and cardiac output in relation to reduced arterial oxygen tensions under light anaesthesia.

cardiac arrest occasionally occurred at light anaesthetic levels (for example, 0.75 per cent end-tidal halothane). Changes in $\mathrm{pH}$ and arterial carbon dioxide tension may alter the response to hypoxia significantly, as may oligaemia. It would be un. justifiable to apply our results to conditions where more severe hypoxaemia, acidosis or oligaemia predominate.

Adrenalectomy and splanchnicectomy destroy, although not completely, the humoral response to systemic hypoxia. ${ }^{5}$ The effect of propranolol which we observed is consistent with the hlockade of a predominantly $\beta$-adtenergic response.

Cullen and Eger ${ }^{*}$ were concerned about the extent to which depth of anaesthesia masks the cardiovascular signs of hypoxaemia in clinical practice. Our investigations show that hypertension, peripheral vasodilation and increase in heart rate are prominent signs during light anaesthesia.

In deep anaesthesia, changes in blood pressure and peripheral circulation in response to hypoxaemia are not dramatic. Changes in cardiac rate and, with trichlorethylene, changes in rhythm seem better guides to the presence of hypoxaemia in ventilated subjects. Since the respiratory response to severe hypoxaemia appears to be prominent even with deep methoxyflurane anaesthesia, ${ }^{6}$ it is perhaps fortunate that most patients subjected to deep anaesthesia are allowed to breathe spontaneously.

\section{Conclusions}

Under light and moderate anaesthesia hypoxaemia causes a rise in cardiac ottput due to increased stroke volume and heart rate. This response is similar whether 
halothane or methoxyflurane anaesthesia is used, and prevents a severe fall in oxygen transport provided the arterial oxygen tension remains above $25 \mathrm{~mm} \mathrm{Hg}$. At lower arterial oxygen tensions the oxygen transport falls despite a significant increase in cardiac output. The clinical signs of hypoxaemia are clear, and, under trichlorethylene anaesthesia, arrhythmias are likely to occur. Peripheral vasodilation accompanies the hypoxaemia. The over-riding response in artificially ventilated dogs anaesthetised with methoxyflurane is sympathetic as it is largely blocked by propranolol.

Under deep anaesthesia, the rise in cardiac output during hypoxaemia is not significant and is unlikely to maintain oxygen transport. Myocardial contractility (as measured by left ventricular $\mathrm{dP} / \mathrm{dt}$ ) rises much less than under light anaesthesia. There is little evidence of additional peripheral vasodilation and some important signs of hypoxaemia are masked in the artificially ventilated subject. Mortality and morbidity rates are significantly high in dogs under deep anaesthesia, in contrast to good recovery rates in dogs under light anaesthesia.

The conclusions are applicable only in the absence of oligaemia, acidosis, anaemia, asphyxia or more severe hypoxia, all of which may significantly alter the response. The role of these factors requires further study.

\section{SUMMAFY}

Beagle dogs were anaesthetised with halothane, trichlorethylene or methoxyflurane, at various end-tidal concentrations and were ventilated to maintain arterial carbon dioxide tension constant.

Under light anaesthesia, severe arterial hypoxaemia caused significant increases in cardiac output, stroke volume and heart rate and a decrease in total systemic vascular resistance. Oxygen transport values during hypoxaemia remained close to control levels measured when the dogs were breathing air, unless the arterial oxygen tension fell below $25 \mathrm{~mm} \mathrm{Hg}$. Then the oxygen transport values fell despite significant increases in cardiac output. The clinical signs of hypoxaemia were clear in the lightly anaesthetised dogs.

Under deep anaesthesia, the rise in cardiac output during hypoxaemia was not significant and the total systemic vascular resistance did not fall. Oxygen transport values decreased from the control levels. Some clinical signs of hypoxaemia were less striking than in the lightly anaesthetised hypoxaemic dogs. Morbidity and mortality rates were high in this group.

We conclude that the cardiovascular response to hypoxaemia was well maintained only in those dogs under light anaesthesia with the agents studied.

\section{RÉSUMÉ}

Nous avons anesthésié des chiens Beagle avec de l'halothane, du trichlorethylene ou du méthoxyflurane, à diverses concentrations expiratoires et nous les avons ventilés de façon à garder constant le $\mathrm{CO}_{2}$ artériel.

Sous anesthésie légère, une hypoxhémie artérielle marquée a entrainé des augmentations du débit cardiaque, du volume systolique, de la fréquence cardiaque et 
une diminution de la résistance vasculaire totale systémique. Durant l'hypoxhémie, les données du transport d'oxygène sont demeurées voisines des taux, chez les témoins, lorsque les chiens respiraient de lair, à moins que la $\mathrm{PaO}_{2}$ ait été inférieure à $25 \mathrm{~mm} \mathrm{Hg}$. Alors les données du transport d'oxygène ont diminué malgré les augmentations importantes du débit cardiaque. Les signes cliniques d'hypoxhémie étaient évidents chez les chiens sons anesthésie légère.

Sous anesthésie profonde, laugmentation du debit cardiaque durant l'hypoxhémie n'a pas été très marquée et la résistance vasculaire totale systémique n'a pas diminué. Les données du transport d'oxygène ont diminué par rapport aux données trouvées chez les témoins. Quelques uns des signes cliniques d'hypoxhémie étaient moins évidents que chez les chiens hypoxhémiques sous anesthésie légère. Dans ce demier groupe le taux de morbidité et de mortalité a été élevé.

Avec les agents employés, nous en venons à la conclusion que la réponse cardiovasculaire à l'hypoxhémie ne s'est maintenue que chez les chiens sous anesthésie légère.

\section{REFERENCES}

1. REcan, M.J. EGEn, E.I., II. Effect of hypothermia in dogs on anzesthetising and apneic doses of inhalation agents. Determination of the anesthetic index (Apnea/MAC). Anesthesiology, 28: 689 (1967).

2. Cullew, D.J. \& Eces, E.I., iI. The effects of bypoxia and isovolemic anemia on the halothane requirement (MAC) of dogs. 3. The effects of hypoxia. Anesthesiology, 32: 28 (1970).

3. CutLEN, D.J. \& EgEk, E.I, II. The effects of halothane on respiratery and cardiovascular responses to hypoxia in dogs. A dose-response study. Anesthesiology, 33: 487 (1970).

4. GonLIN, R. LEwis, B.M. Circulatory adjustments to hypoxia in dogs. J. Appl. Physiol. 7 : 180 (1954).

5. Hatcher, J.D. \& Jennings, D.B. Evidence for the Role of Humoral Mechanisms in the Cardiovascular Responses to Hypoxia and Anaemia in International Symposium on Cardiovascular and Respiratory Effects of Hypoxia. Kingston, Ontario, 1965. Proceedings. Edited by J.D. Hatcher and D.B. Jennings, Basel, Karget, 1966, PP. 174-190.

6. Nisbet, H.I.A. Unpublished observations. 